\title{
A CONTRIBUIÇÃO DE ERIC HOBSBAWM (1917-2012) PARA COM A PRODUÇÃ̃O DO CONHECIMENTO HISTORIOGRÁFICO'
}

José Luís Sanfelice²

\section{RESUMO}

O objetivo da presente apresentação é registrar a forma pela qual o historiador E. Hobsbawm considera ter vivenciado a produção da historiografia ao longo do século XX. Suas referências são ao positivismo, ao marxismo, à Escola dos Annales e às tendências pós-modernas. Sua avaliação é desfavorável às últimas tentativas de produção do conhecimento histórico e, a esperança é depositada nos novos historiadores que necessitam ter sua atenção dirigida à interpretação materialista da história, por ela possuir mais substância do que imaginam.

Palavras-chave: E. Hobsbawm - historiografia - produção do conhecimento materialismo histórico.

\section{THE CONTRIBUTION OF ERIC HOBSBAWM (1917-2012) TO THE PRODUCTION OF HISTORIOGRAPHICAL KNOWLEDGE}

\begin{abstract}
The aim of the current presentation is to register the manner in which the historian E. Hobsbawm considers to have experienced the production of historiography throughout the XX century. His references are to the positivism, to the Marxism, to the Annales School and to the post-modern tendencies. His evaluation is unfavourable to the last attempts of production of historical knowledge, and the hope is deposited in the new historians who need to have their attention directed to the materialistic interpretation of History, since it possesses more substance than they imagine.
\end{abstract}

Keywords: E. Hobsbawm - historiography - production of knowledge - historical materialism

A missão sugerida a essa mesa é, no seu ponto de partida, quase impossível de ser atingida no seu ponto de chegada. Trata-se, nada mais nada menos, de prestar uma homenagem a três brilhantes intelectuais do século XX. Todos eles longevos e responsáveis por uma imensa produção. Sempre ficará ausente alguma observação relevante que deveria ter sido feita e, não o foi. Quero crer, entretanto, que no trabalho coletivo que daqui resultará, sejam diminuídas as lacunas que, ainda assim, persistirão ${ }^{3}$. Vou me restringir a Eric Hobsbawm (1917-2012) e a alguns aspectos da sua contribuição para a produção do conhecimento .

Com uma vida de quase um século, boa parte dela dedicada ao estudo e à escrita da história, resulta daí uma imensa obra que até pode ser adjetivada de monumental. Não vou nem me dispor a fazer uma apresentação biográfica ou um arrolamento comentado da sua, perdoem-me, fantástica produção. Obra monumental e produção 
fantástica pela quantidade, qualidade, erudição, rigor metodológico e coerência assumida nos campos da historiografia, da política e inserção no seu tempo.

Como o tema geral desse evento é a "Produção do conhecimento no limiar do século XXI: tendências e conflitos", considerei mais oportuno destacar uma reflexão que Hobsbawm realiza em seu livro Tempos Interessantes - Uma vida no século XX, publicado entre nós na passagem do século XX para o XXI pela Companhia das Letras e, onde ele faz uma indagação que se torna extremamente pertinente para esta ocasião.

A pergunta é: "Que aconteceu, durante minha vida, com a maneira de escrever a história?". Pela sua longa vida, a pergunta significa, para nós, o que aconteceu com a maneira de escrever a história durante todo o século XX?

Primeiro um testemunho: "Em minha geração não se ensinava sistematicamente na Grã-Bretanha aquilo que Marc Bloch chamou 'o ofício do historiador'. Íamos aprendendo como podíamos. Muito dependia de quem encontrássemos no tempo de estudantes de graduação" (p. 312).

Mas, o grande conflito que dividia a profissão de historiador entre as décadas de 1890 e 1970 foi, de um lado, a hipótese convencional positivista: a história é a política do passado, no interior dos Estados - nações e suas relações com outros. De outro lado, a história que deve tratar das estruturas e mudanças das sociedades e culturas, uma menção ao marxismo e aos Annales. No primeiro caso a história como narrativa e, no segundo, a história como análise e síntese.

"Os jovens marxistas como eu, que começavam a carreira profissional de historiadores, viam-se agora lançados a essa batalha entre a velha e a nova história..." (p. 315). Entenda-se a batalha entre positivistas x marxistas e seguidores dos Annales. "Uma inovação na qual me vi diretamente envolvido foi sobre história social ... Com efeito se fazia muito pouca história social ...” (p. 316-317). Entretanto, a atuação dos Annales, dos marxistas e dos seus críticos, já por volta da segunda metade do século $\mathrm{XX}$, fez com que a fisionomia da historiografia se tornasse visível.

Hobsbawm esclarece que entre as diversas escolas de historiógrafos modernizados (franceses, alemães, ingleses) havia diferenças ideológicas e de politização decorrentes da Guerra Fria. Mas estavam todos no mesmo caminho, lutando contra os mesmos adversários e sabiam disso: essencialmente eram contrários ao positivismo.

Em outras palavras, queriam um campo histórico mais ampliado ou democratizado, além de metodologicamente sofisticado. Favoreciam uma história fertilizada pelas ciências sociais ...

...os modernizadores históricos, embora unidos contra os conservadores históricos, nada tinham de homogêneos, política ou ideologicamente (p. 318).

Segundo o 'depoimento' de Hobsbawm, vê-se que nos trinta anos após a Segunda Guerra Mundial, os tradicionalistas históricos estavam na retaguarda de uma guerra perdida. Os modernistas avançavam na maioria dos países ocidentais em que a história florescia livremente.

O jornal americano Daedalus organizou em 1970 uma reunião bastante otimista, para não dizer triunfalista, a fim de avaliar o estado da história. A não ser os (defensivos) porta-vozes da história militar e política, a assembleia foi dominada pelos modernizadores - britânicos, 
franceses, e, entre os menos de quarenta anos, pelos americanos. A essa altura havia sido encontrada uma bandeira comum para a frente popular dos inovadores, que estava longe de ser homogênea: 'história social'. Coadunava-se com a radicalização política da população estudantil em dramática expansão na década de 1960. O termo era vago, às vezes capaz de causar equívocos, porém, como escrevi na época, ao notar o 'estado notavelmente florescente desse campo': 'É um bom momento para ser historiador social. Até mesmo aqueles entre nós que jamais desejaram ser chamados por esse nome não o renegarão' (p. 319-320).

E, surge uma confissão que indica os condicionantes para o exercício do 'ofício de historiador': Hobsbawm declara que se tornou essencialmente um historiador do século XIX por conta da censura historiográfica do Partido Comunista no qual militava e em decorrência das interpretações dos historiadores soviéticos sobre os acontecimentos nos quais estavam todos imersos. "Felizmente me abstive da história do século XX até que este já estava quase terminado..." (p. 321).

É importante observar os apontamentos de Hobsbawm sobre uma historiografia eurocêntrica, pois antes da guerra a história extra-européia interessou a poucos historiadores. Uma concessão é feita aos historiadores marxistas pois ao se posicionarem contrários ao imperialismo capitalista, voltaram sua atenção para o mundo colonial. Com a descolonização dos antigos impérios e a simultânea ascensão dos Estados Unidos como potência mundial, a história extra-européia passou a ter vida própria. "A história do mundo como história de todo o globo emergiu na década de 1960, com o evidente progresso da globalização" (p. 322).

Um quase lamento: "A história, infelizmente, continua a ser uma série de nichos de mercado para os que escrevem e para os que lêem .... Em retrospecto, esse provincianismo foi talvez a maior debilidade do tema em meu tempo de vida" (p. 323). Evidentemente as razões pelas quais o autor defende o 'ofício do historiador' são mais amplas e complexas: “... a maioria dos historiadores, inclusive todos os competentes, sabe que ao investigar o passado, até mesmo o passado remoto, estão igualmente pensando e expressando opiniões a respeito do presente e suas questões, e falando a respeito delas. Compreender a história é importante tanto para os cidadãos como para os especialistas...” (p. 311), consequentemente não pode se reduzir a um nicho de mercado.

E Hobsbawm se dá conta do que ocorreu na historiografia ao se aproximar o final do século XX. Ele registra:

$\cdots$

por volta de 1970 parecia razoável supor que estava ganha a guerra pela modernização da historiografia, que começara na década de 1890 . ... Não que os modernizadores, pelo menos exceto os franceses inimigos da 'história dos acontecimentos', necessariamente propusessem uma hegemonia da história econômica e social, ou até mesmo relegar a história política, sem falar na história das idéias e da cultura. Embora acreditassem que a história deve explicar e generalizar, sabiam que ela não é como as ciências naturais. ... Entretanto, em poucos anos o panorama mudara completamente: (desapareceu a distinção entre o importante e o trivial e desapareceu o sentido de prioridades) (p, 323). 
Houve movimento de mudança para longe dos modelos históricos ou 'os grandes porquês', um movimento de 'chave analítica para a descritiva', da estrutura econômica e social para a cultura, da recuperação dos fatos para a recuperação dos sentimentos, do telescópio para o microscópio. ... Talvez houvesse também um elemento daquela curiosa desconfiança intelectual pelo racionalismo das ciências naturais que ficaria ainda mais na moda à medida que o século chegava ao fim. Não que se possa vislumbrar um retorno da história estrutural para a narrativa, entre os acadêmicos, ou à história política de estilo antigo. De qualquer maneira, tanto quanto sei os historiadores das gerações jovens nos últimos trinta anos não produziram qualquer obra-prima histórica narrativa e não analítica. ... No entanto, a simples extensão do ocultamento de temas evidentemente importantes, ou sua relegação ao silêncio, a partir de 1945, deu ampla oportunidade a que houvesse um preenchimento de lacunas baseado em arquivos, ou a 'história dos acontecimentos' (p. $324)$.

$\cdots$

Embora os historiógrafos modernos que lutaram com tanto êxito contra os antigos até o final da década de 1960 constituíssem uma aliança de que faziam parte os marxistas, o desafio a sua supremacia não veio da direita ideológica ... as gerações de esquerda após a década de 1960 desejavam particularmente outra coisa. Porém, repito, essa não foi uma reação específica contra o marxismo ...

Pelo menos uma parte das mudanças na história acompanharam a extraordinária revolução cultural da segunda metade da década de 1960, cujo epicentro estava nas universidades e mais especialmente nas artes e humanidades. Não era tanto um desafio intelectual quanto uma mudança de humor ... a história não era tanto uma forma de interpretar o mundo, mas um meio para a autodescoberta coletiva (feminismo?), ou , na melhor das hipóteses para obter reconhecimento coletivo (minorias?) (p. 325-26).

Face às mudanças na historiografia, uma clara menção aos novos paradigmas e ao que entre nós se denomina de Nova História, Hobsbawm adverte sobre alguns perigos do novo embate e que bem nos serve nessa já segunda década do século XXI. Sintetizo: o perigo dessas novas posições é que elas solapam a universalidade do universo do discurso, que é a essência de toda a história como disciplina erudita e intelectual (particular x geral); prejudica aquilo que os antigos e modernos tinham em comum, isto é, a convicção de que as investigações dos historiadores, mediante regras geralmente aceitas de lógica e de evidência, distinguem entre fato e ficção, entre o que pode ser estabelecido e o que não pode, aquilo que é e aquilo que gostaríamos que fosse (tendências de se converter a história em literatura ou de se tomar o discurso como a própria realidade); mais perigoso ainda: as pressões políticas sobre a história vindas dos Estados ou dos grupos de identidade; a moderna sociedade mediática que confere ao passado proeminência sem precedentes e potencial de mercado. "Mais do que nunca a história é atualmente revista ou inventada por gente que não deseja o passado real, mas somente um passado que sirva a seus objetivos. Estamos hoje na grande época da mitologia histórica. A defesa da história por seus profissionais é hoje mais urgente na política do que nunca. Somos necessários” (p. 326). 
O futuro? "... dispomos de uma estrutura adequada para uma história genuinamente global, restaurada a seu devido lugar central, nem englobada nas humanidades ou nas ciências naturais e matemáticas, nem tampouco separadas delas, porém essencial a ambas" (p. 327).

Finalmente, acredito que já se dirigindo aos historiadores do século XXI:

Os jovens historiadores necessitam que sua atenção seja dirigida nos dias de hoje para a interpretação materialista da história tanto quanto, ou talvez até mais, na época em que ela era condenada como propaganda totalitária, pois até mesmo as modas acadêmicas igualmente a desprezam. Afinal de contas, venho procurando convencer as pessoas durante mais de meio século de que a história marxista tem mais substância do que imaginam, e se a associação do nome do historiador a ela ajuda nesse trabalho, tanto melhor (p. 333).

E nada indica que Hobsbawm tenha mudado de idéia até a sua morte. Tendo vivenciado o movimento da escrita da história por todo o século $\mathrm{XX}$, os seus registros soam como depoimentos que trazem consigo as diferentes maneiras que a produção do conhecimento histórico praticou. Suas esperanças de que os jovens historiadores atentem para a interpretação materialista da história, parecem decorrer da sua convicção da substância dela e também da constatação de que pouco se realizou de significativo nas décadas finais do século XX, sob a inspiração de outras referências.

\section{Referência}

HOBSBAWM, E. Tempos interessantes. Uma vida no século XX. São Paulo: Companhia das Letras, 2002.

\section{Notas}

1. Participação na mesa de encerramento do X Colóquio Nacional e III Colóquio Internacional do Museu Pedagógico da Universidade Estadual do Sudoeste da Bahia (UESB), realizado em Vitória da Conquista de 28 a 30 de agosto de 2013, sobre a 'Produção do conhecimento no limiar do século XXI: tendências e conflitos'.

Participation in the closure table of the X National Colloquy and the III International Colloquy of the Pedagogical Museum of the State University of the South West of Bahia (UESB), which took place in Vitória da Conquista from the $28^{\text {th }}$ to the $30^{\text {th }}$ of August, 2013, about the "Production of knowledge on the threshold of the XXI century: tendencies and conflicts".

2. Professor Titular em História da Educação da UNICAMP, aposentado e colaborador. Pesquisador do Grupo de Estudos e Pesquisas 'História, Sociedade e Educação no Brasil' (HISTEDBR).

3. Participaram da mesa os professores doutores Paolo Nosella (UFSCar), Magdalena Gonzáles (Universidade Complutense de Madri) e Jorge Marco (Universidade Complutense de Madri). A mediação da mesa esteve sob a responsabilidade do mestre Ruy Hermann de Araújo Medeiros.

4. Mario A. Monacorda (9/12/1914 - 17/2/2013) e Julio Aróstegui (1939-2013) foram os outros historiadores referenciados na ocasião. 